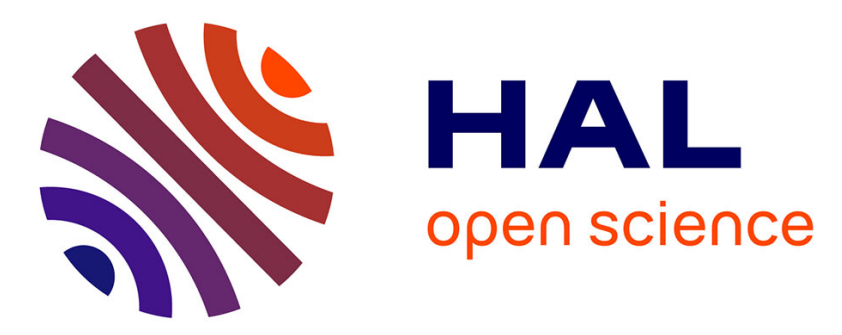

\title{
Intestinal Availability and Metabolic Effects of Dietary Camelina Sphingolipids during the Metabolic Syndrome Onset in Mice
}

Dominique Hermier, Annaig Lan, Fredeŕique Tellier, Anne Blais, Marta Culetto, Veŕonique Mathe, Yannick Bellec, Lionel Gissot, Philippe Schmidely, Jean-Denis Faure

\section{To cite this version:}

Dominique Hermier, Annaig Lan, Fredeŕique Tellier, Anne Blais, Marta Culetto, et al.. Intestinal Availability and Metabolic Effects of Dietary Camelina Sphingolipids during the Metabolic Syndrome Onset in Mice. Journal of Agricultural and Food Chemistry, 2020, 68 (3), pp.788-798. 10.1021/acs.jafc.9b06829 . hal-02463037

\section{HAL Id: hal-02463037}

\section{https://hal-agroparistech.archives-ouvertes.fr/hal-02463037}

Submitted on 21 Oct 2021

HAL is a multi-disciplinary open access archive for the deposit and dissemination of scientific research documents, whether they are published or not. The documents may come from teaching and research institutions in France or abroad, or from public or private research centers.
L'archive ouverte pluridisciplinaire HAL, est destinée au dépôt et à la diffusion de documents scientifiques de niveau recherche, publiés ou non, émanant des établissements d'enseignement et de recherche français ou étrangers, des laboratoires publics ou privés. 
1 ?] ? syndrome onset in mice.

3 Dominique Hermier ${ }^{1}$, Annaïg Lan $^{1}$, Frédérique Tellier $^{2}$, Anne Blais ${ }^{1}$, Marta Grauso Culetto ${ }^{1}$

4 Véronique Mathé ${ }^{1}$, Yannick Bellec ${ }^{2}$, Lionel Gissot ${ }^{2}$, Philippe Schmidely ${ }^{3}$, Jean-Denis Faure ${ }^{2}$.

51 , UMR Physiologie de la Nutrition et du Comportement Alimentaire, AgroParisTech, INRA, Université Paris-Saclay, 75005, Paris, France

72 , Institut Jean-Pierre Bourgin, INRA, AgroParisTech, CNRS, Université Paris-Saclay, 78000, Versailles, France

$9{ }^{3}$, UMR Modélisation systémique Appliquée aux Ruminants, AgroParisTech, INRA, Université 10 Paris-Saclay, 75005, Paris, France

$12 *$, corresponding author:

Dominique Hermier, UMR Physiologie de la Nutrition et du Comportement Alimentaire, AgroParisTech, 16 rue Claude Bernard, F-75005 Paris, France

Phone : 33(1)44087246

Fax: (33)144081858

Email: dominique.hermier@agroparistech.fr 
ABSTRACT.

Sphingolipids appear as a promising class of components susceptible to prevent the onset of the metabolic syndrome (MetS). Gut availability and effects of Camelina sativa sphingolipids were investigated in a mouse model of dietary-induced metabolic syndrome. Seed meals from two Camelina sativa lines enriched respectively in C24- and C16- $\mathrm{NH}_{2}$-glycosyl-inositolphosphoryl-ceramides $\left(\mathrm{NH}_{2} \mathrm{GIPC}\right)$ were used in hypercaloric diets. After 5 weeks on these two hypercaloric diets, two markers of the MetS were alleviated (adiposity and insulin resistance) as well as inflammation markers and colon barrier dysfunction. A more pronounced effect was observed with the C16- $\mathrm{NH}_{2}$ GIPC-enriched $\mathrm{HC}$ diet, in particular for colon barrier function. Despite a lower digestibility, $\mathrm{C} 16-\mathrm{NH}_{2} \mathrm{GIPC}$ were more prevalent in the intestine wall. Sphingolipids provided as camelina meal can therefore counteract some deleterious effects of a hypercaloric diet in mice at the intestinal and systemic levels. Interestingly, these beneficial effects seem partly dependent on sphingolipid acyl chain length.

Key words: sphingolipid, Camelina sativa, metabolic syndrome, digestibility, acyl chain. 


\section{INTRODUCTION}

The metabolic syndrome (MetS) is a cluster of abnormalities including visceral obesity, dyslipidemia, hyperglycemia, and increased blood pressure, which results in a higher risk of cardiovascular diseases and type-2 diabetes ${ }^{(1)}$.

Its prevalence is increasing worldwide and makes it a major public health challenge. This increase is associated with several features of lifestyle such as physical inactivity, psychosocial stress, environmental contaminants, and, as a major determinant, dietary habits ${ }^{(2)}$. High caloric intake, typical of Western-type diet rich in saturated fatty acids (SFA) and sugars, is a major causative factor of the onset of the MetS, which is characterized by early events such insulin resistance (IR) and a low-grade inflammation (LGI) ${ }^{(3,4)}$. These alterations are known to originate, at least partly, from an allostatic stress due to the Western-type diet, which is characterized by microbial dysbiosis ${ }^{(5)}$, together with local inflammation $^{(6)}$ and physiological dysfunction of the intestinal wall ${ }^{(3)}$. The resulting endotoxemia enhances the low-grade inflammation (LGI) at the systemic level, which, in turn, amplifies the initiation of the MetS $(7,8)$ In addition to the rodent studies, both observation and intervention human studies confirmed the link between nutrients, gut dysfunction, LGI and initiation of the MetS, and in particular IR ${ }^{(8,9)}$.

In consequence, new preventive and therapeutic strategies for MetS, including lifestylebased changes involving nutrition, must be established, tested and improved in specifically susceptible and vulnerable people, such as the at-risk, obese subjects. In these patients, the challenge is to prevent or delay the onset of IR and low-grade inflammation, and of cardiometabolic complications. Among the different possible solutions are diet changes and/or diet complementation.

As part of dietary candidates susceptible to prevent or alleviate the onset of the MetS, and 
particularly of IR, sphingolipids (SL) appear as a new and promising class of components. Indeed, body SL originate from endogenous synthesis, but may also be provided by the diet from animal or vegetal products. SL are composed of a sphingoid base (or long-chain base, LCB) acylated by a long or very long-chain FA and bearing a more or less complex polar head group ${ }^{(10)}$. They are essential components of cell membranes and are involved in cell signalling in both plants and animals. They are associated, together with animal cholesterol or plant phytosterols, into membrane micro-domains (caveolae and lipid rafts) ${ }^{(11)}$. These micro-domains are more ordered and less fluid than the rest of the plasma membrane, which favours docking, clustering and functionality of insulin receptor and other membrane receptors ${ }^{(11,12)}$. Interestingly, the length of the SL acyl chain is an important structural feature modulating the properties of these micro-domains and subsequent translocation and downstream signalling of insulin receptor ${ }^{(13)}$. A number of disparate, but convincing data, suggest that some plant SL (phytoSL) would improve some features of the MetS, such as dyslipidemia $^{(14,15)}$, IR/glucose intolerance ${ }^{(15-18)}$ and non-alcoholic steatohepatitis ${ }^{(14,18-20)}$. There is also some evidence that dietary SL from both animal and plant origin may exert anti-inflammatory effects at the extra-digestive level, including in the postprandial state ${ }^{(21,}$ 22).

Other beneficial effects of phytoSL have been described at the intestine level, in mice models of chemically-induced colorectal cancer or inflammatory bowel diseases ${ }^{(23-28)}$. In contrast, when it comes to nutritionally-induced rather than chemically-induced, allostatic intestinal stress, it remains unknown if dietary phytoSL may alleviate microbial dysbiosis and/of gut barrier function alterations, which could explain some beneficial systemic consequences.

The mechanisms by which phytoSL exert their beneficial effects are still not elucidated and 
since it is a large and diversified lipid family, the role of the different structural components (polar head, acyl chains, long chain base) remains to be deciphered. Indeed, plants have a large variety of SL with more than 300 molecular species, some of which being tissue specific (29). They are characterized by specific polar heads like glycosyl-inositol-phosphorylceramides (GIPC) and LCB like phytosphingosine (PHS, t18:1). Seeds also accumulate specific amino-derivate GIPC $\left(\mathrm{NH}_{2} \mathrm{GIPC}\right)^{(29)}$.

Taken together, available data suggest that plant-derived SL can have beneficial effects on the MetS onset. However, all previous studies were performed by using purified SL and, most often, plant SL were administered orally or intra-peritoneally, and not as diet ingredient. The objective of the present study was therefore to assess (i) whether plant SL provided as part of the diet (i.e. as a food ingredient in a food matrix) could counteract MetS onset and (ii) whether SL acyl chain length is important in modulating the physiological and metabolic impact of dietary phytoSL. Because bioavailability is an essential prerequisite to extra-digestive effects, digestibility of phytoSL with different acyl chain length had also to be determined. Plant SL originating from two isogenic camelina cultivars in which SL were differing only by their fatty acid (FA) chain length were provided as seed meal to mice fed for 5 weeks with high-fat/high sucrose diets. The first outcome was to assess the bioavailability of dietary phytoSL at the digestive level, by using plant sphingolipidomic profiling, and their possible impact on intestinal function. The second one was to evaluate if dietary phytoSL could slower the onset of the MetS, especially as regards dyslipidemia and IR. Finally, the hypothesis that acyl chain length may modulate digestibility and bioactivity of phytoSL was also tested for both the outcomes. 
MATERIALS AND METHODS

Selection of C16-SL accumulating camelina line. Camelina sativa cultivar "Céline" was grown in glasshouse conditions as described previously ${ }^{(30)}$. To generate plants accumulating SL rich in C16 FA (C16-SL), the coding sequence of the Arabidopsis ceramide synthase AtLOH2 (At3g19260) was PCR amplified using LOH2EcoRI-F and LOH2Xhol-R primers modified with EcoRI and Xhol restriction enzymes (LOH2EcoRI-F, GGAATTCATGGAATCGGTATCATCACG; LOH2Xhol-R, CCGCTCGAGCTAATCATCATCATCCTCTG) and cloned behind the soybean glycinin promoter into the pBinGlyRed2 vectors after removal of the Luciferase coding sequence using the EcoRI/Xhol enzymes. Plants were transformed by flower dip infiltration with Agrobacterium tumefasciens carrying pBinGlyRed2::AtLOH2 and T1 seeds were selected based on their red fluorescence ${ }^{(31)}$. A total of $107 \mathrm{~T} 2$ progeny were produced and screened for their respective seed SL content by LC-MS/MS. Eight T3 progeny were eventually selected and amplified and rescreened for their seed SL content. A homozygous line named $\mathrm{LOH}_{2}^{\mathrm{Y}}$ with the highest C16-SL content was finally selected and amplified as T4 and T5 generations. Complete SL profile was carried out on T5 seeds, as described below.

A total of 1476 wild type camelina and $1593 \mathrm{LOH}^{\Upsilon}{ }^{\mathrm{T}} \mathrm{T} 4$ plants were cultivated side by side in the glasshouse, resulting in the production of $6.1 \mathrm{~kg}$ of Céline seeds (of which SL-FA are mostly $\mathrm{C} 24$ ) and $5.4 \mathrm{~kg}$ of $\mathrm{T} 5 \mathrm{LOH} 2^{\mathrm{Y}}$ seeds (rich in C16-SL). Camelina seeds were crushed with an Oilprinz KK8 F universal (Kern Kraft, Reut, Germany) at $60 \mathrm{rpm}$ and with opening of $8 \mathrm{~mm}$ to produce CamC24 and CamC16 meal and oil from Céline and $\mathrm{LOH}_{2}^{\mathrm{Y}}$ seeds respectively. Macronutriment composition of the camelina meal was determined as previously described ${ }^{(32)}$ and was (in weight \%): 36.5/39.4 protein, 19.7/19.8 lipid, 29.4/28.8 fibre, 5.79/5.83 ashes and 5.70/5.81 humidity for the CamC24 and CamC16, respectively. Fibre typology was the same in both meals (data not shown). 
Animals and diets. Thirty-three 7-week old male C57BL/6JOlaHSD mice (Envigo, Gannat,

France) were housed in individual cages with wired floor, at $22 \pm 1^{\circ} \mathrm{C}$ under 12 -h light/dark cycles (light on at 07:00 am) and acclimated to local conditions for 1 week. During the last 3 days of the week, 27 mice were progressively switched from the standard pelleted chow diet (SAFE A04, Augy, France) to the control hypercaloric (HC-Con) diet (see below). At 8 weeks of age, mice were divided into 4 groups and fed during 5 weeks with either the same chow diet as before (normocaloric diet, NC group, $n=6$ ) or one of the three hypercaloric $(H C)$ diets, two providing one of the two camelina meals (HC-CamC24 and HC-CamC16, n=9) and the third one a control HC diet (HC-Con $n=9)$ (Supplemental Table 1). Mice had free access to food and tap water. Individual body weight was recorded weekly. The study was performed according to the European directive for the use and care of laboratory animals (2010/63/UE), and received the agreement of the local animal ethics committee and of the ministerial committee for animal experimentation (Ref 20151I0317422745.v4-APAFIS\#2701).

$\mathrm{HC}$ diets were prepared freshly twice a week, stored at $4^{\circ} \mathrm{C}$, and provided daily to mice as soft pellets. CamC24 and CamC16 meals from the commercial Céline cultivar and $\mathrm{LOH}^{\Upsilon}{ }^{\Upsilon}$ line were incorporated into the HC diets (respectively HC-CamC24 and HC-CamC16). Camelina oil obtained from Céline seed crushing was kept at $4^{\circ} \mathrm{C}$ and incorporated into the HC-Con diet at the same level as in the two HC-CamC24 and HC-CamC16 diets. It contains as previously described mostly polyunsaturated FA (53\%) and monounsaturated FA (29\%), as previously described ${ }^{(31)}$. SL analysis of this oil showed the absence of $\mathrm{NH}_{2} \mathrm{GIPC}$, the major $\mathrm{SL}$ in both

Sphingolipid were extracted from camelina meals, oils and diets, as described previously 
$\mathrm{NH}_{2}$ GIPC, which was the major SL in both meals (92\%) (Supplemental Table 2). In contrast, C24- $\mathrm{NH}_{2}$ GIPC accounted for $82 \%$ of total $\mathrm{NH}_{2}$ GIPC in CamC24, whereas C16- $\mathrm{NH}_{2} \mathrm{GIPC}$ accounted for $90 \%$ of total $\mathrm{NH}_{2}$ GIPC in CamC16. The amount of camelina meals to be incorporated into the HC-CamC24 and HC-CamC16 diets $(107 \mathrm{~g} / \mathrm{kg})$ was calculated according to the SL content of the camelina meals, the mice food intake (about $4 \mathrm{~g} / \mathrm{d}$ for a $\mathrm{HC}$ diet) and the amount of purified plant SL given to rodents in the literature $(4-8 \mathrm{mg} / \mathrm{d}$ in mice, without indication of their body weight) ${ }^{(14,16)}$. SL profile of the HC-CamC24 and HC-CamC16 diets reflected that of the respective meals, with $\mathrm{NH}_{2}$ GIPC being the major SL with mostly by 24 carbons FA in CamC24 meal, and by 16 carbons FA in CamC16 meal (Table 1). As expected, HC-Con diet contained very little $\mathrm{NH}_{2}$ GIPC, whereas the NC diet was surprisingly rich in SL, and especially in $\mathrm{NH}_{2} \mathrm{GIPC}$, probably as a consequence of the high level of plant-based materials (e.g. soya bean) in the commercial chow.

In vivo measurements and sample collection. Food intake during $48 \mathrm{~h}$ was monitored after $6 \mathrm{~d}$ and $4 \mathrm{wk}$ on the experimental diets. Feces were collected and weighed for further lipidomics at the end of the $48 \mathrm{~h}$. Part of the feces was freeze-dried before assaying the dry matter content ${ }^{(32)}$. Apparent digestibility of the dry matter was calculated as follows: (intake-feces content)/intake*100. SL apparent digestibility was calculated by applying the same formula to SL content measured in food and feces.

The body composition (fat mass and lean mass) was measured in vivo after 3 weeks on the experimental diets by dual energy X-ray absorptiometry (DEXA), using a Lunar PIXImus densitometer (GE Medical Systems, Buc, France). The stability of the device was controlled by a measurement of a phantom before each session. The mice were anesthetized by isoflurane inhalation during the measurement. Analysis of the images was performed with 
the software provided with the device (Lunar PIXImus v2.10, GE Medical Systems, Buc, France), using auto-thresholding.

An oral glucose tolerance test (OGTT) was performed after 3 weeks on the experimental diets. Six hours fasted mice were weighed and a blood sample ( $25 \mu \mathrm{L})$ was taken from the tail vein $\sim 15$ min before (t0) gavage, then after $15,30,60$, and $120 \mathrm{~min}$ following orally administration of a glucose solution $(2 \mathrm{~g} / \mathrm{kg})$. Blood glucose concentration was immediately assayed using a standard glucometer (Onetouch, LifeScan, Boulogne-Billancourt, France). Blood was centrifuged $\left(10 \mathrm{~min}, 1600 \mathrm{~g}, 4^{\circ} \mathrm{C}\right.$ ) and plasma stored at $-20^{\circ} \mathrm{C}$ for subsequent assay of insulin.

After 5 weeks on the experimental diets, mice were fasted for $6 \mathrm{~h}$. After a blood sample has been taken from the tail vein for glucose determination, mice were deeply anesthetized by isoflurane inhalation (IsoFlo, Axience, Pantin, France). Blood was taken by cardiac puncture before mice were euthanized by exsanguination. The abdominal cavity was then opened and the following parts were removed and weighed: liver, epididymal adipose tissue (EpAT), kidneys, spleen, small intestine, caecum and colon. The luminal contents of the caecum and the colon were removed and weighed. Jejunum, colon and EpAT samples were snap-frozen in liquid nitrogen and stored at $-80^{\circ} \mathrm{C}$. Blood samples were centrifuged as described above for plasma extraction and storage.

Ex vivo intestinal measurements. To assess potential changes in intestinal barrier function, electrophysiological measurements were performed as previously described ${ }^{(33)}$ with the following modifications: each mouse proximal colon was opened along the mesenteric line and mounted on an EasyMount Ussing chamber insert (Physiologic Instrument Inc, San Diego, CA, USA) with an exposed area of $0.2 \mathrm{~cm}^{2}$. Mounted tissues were left to equilibrate 
their trans-epithelial potential $\left(V_{\mathrm{t}}, \mathrm{mV}\right) 45 \mathrm{~min}$ before clamping them to $0 \mathrm{mV}$ to obtain the short-circuit current $\left(I_{\mathrm{sc}}, \mu \mathrm{A} / \mathrm{cm}^{2}\right)$. The trans-epithelial electrical conductance $\left(G_{\mathrm{t}}, \mathrm{mS} / \mathrm{cm}^{2}\right)$ was obtained using the Ohm law by the voltage deviation when the tissue was current pulsed with $\pm 5 \mu \mathrm{A}$.

Paracellular permeability to fluorescein isothiocyanate (FITC)-dextran 4000 (FD4, Sigma) was determined during a 100-min period in Ussing chambers. Soon after tissue mounting $\left(t_{0}\right)$, FD4 was added to the chamber mucosal side at the final concentration of $0.250 \mathrm{mg} / \mathrm{mL}$. Serosal samples were collected at $t_{0}$ and after $100 \mathrm{~min}$. To test for tissue viability at the end of the experiment, carbachol $\left(\mathrm{CCh}, 10^{-4} \mathrm{M}\right)$ was applied at the serosal side verifying the activation of the calcium-dependent chloride secretion by the $I_{\mathrm{sc}}$ increase.

Biochemical analyses and physiological measurements. Blood glucose concentration was determined with an Accu-Chek ${ }^{\circledR}$ glucometer (Roche Diagnostics, Meylan, France). Plasma triglyceride concentrations were determined by colorimetric enzymatic methods using a commercial kit adapted for use in a 96-well microplate reader (Molecular Devices, SaintGrégoire, France), and obtained from Randox (Roissy, France) ${ }^{(34,35)}$. Plasma insulin was determined using enzyme-linked immuno-assay (Mouse insulin ELISA, Mercodia, Paris, France). Homeostasis model assessement of insulin resistance (HOMA-IR) index was calculated using the formula: [fasting insulin (pmol/L) x fasting glucose (mmol/L)]/22.5.

Sphingolipidomics. SL were extracted from feces, jejunum and colon as described previously (36). A volume of $500 \mu \mathrm{L}$ isopropanol:hexane:water (55:20:25, v/v) and $10 \mu \mathrm{L}$ standard mix [0.01 nmol of C12-Cer (d18:1-h12:0), $0.1 \mathrm{nmol}$ of C12-GluCer (d18:1-h12:0) and $0.2 \mathrm{nmol}$ of ganglioside (GM1)] were added to material and ground using a Polytron homogenizer. The 
plunger was rinsed with $500 \mu \mathrm{L}$ of extraction solvent and the sample incubated at $60^{\circ} \mathrm{C}$ for

231

232

233

234

235

236

237

$15 \mathrm{~min}$. After centrifugation at $4000 \mathrm{rpm}$ for $5 \mathrm{~min}$ at room temperature, the supernatant was recovered and the pellet extracted once more with $1 \mathrm{~mL}$ of solvent. Supernatants were combined and dried with a speed Vac. Then the samples were incubated at $50^{\circ} \mathrm{C}$ for $1 \mathrm{~h}$ with $500 \mu \mathrm{L}$ of $33 \%$ methylamine solution in ethanol-water (7:3) and dried under nitrogen and resuspended by sonication in $100 \mu \mathrm{L}$ of tetrahydrofuran-methanol-water (2:1:2) containing $0.1 \%$ formic acid and filtrated prior to analysis by liquid chromatography coupled to mass spectrometry (UPLC- MS/MS). UPLC- MS/MS analyses were carried out on a Waters Acquity UPLC system coupled to a Waters Xevo tandem quadrupole mass spectrometer equipped with an ESI source (Waters, Milford, MA, USA). Chromatographic conditions, mass spectrometric parameters, and multiple reaction monitoring (MRM) methods were defined as described previously ${ }^{(29)}$.

Gene expression. Total RNA was extracted from EAT and colon samples using Trizol reagent (Invitrogen, Carlsbad, CA, USA). qRT-PCR was performed with mouse-specific primers (Eurogentec, Angers, France) to quantify mRNA level of the following genes : interleukin-6

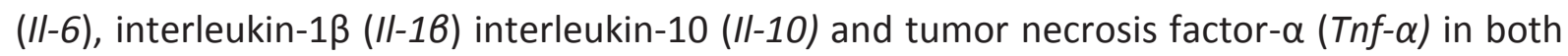
EAT and colon, plasminogen activator inhibitor-1 (Pai-1) and monocyte chemoattractant protein-1 (Mcp-1) in EAT, and claudin $1(C / d n 1)$ and zonula occludens (Tjp1) in the colon. After cDNA synthesis from mRNA using High Capacity cDNA Reverse Transcription Kit (ThermoFisher-Life Technologies, Les Ulis, France), Real-Time PCR was performed subsequently on cDNA using the power SYBR Green PCR master mix and StepOne Real-Time PCR system (ThermoFisher-Life Technologies, Les Ulis, France). cDNA samples were assayed 
in triplicate and gene expression levels for each sample were normalized relative to hypoxanthine-guanine phosphoribosyltransferase gene (Hprt) with $2^{-\Delta \Delta C t}$ calculation.

Statistical analyses. Data are reported as means \pm standard deviations. They were analysed using the XLSTAT application (Addinsoft, Paris, France). Significance level was set at $P<0.05$. The effects of energy level (HC vs NC) and of camelina meal (HC-Con vs HC-CamC16/C24) were tested using a 2-way ANOVA. When diet effect was significant, differences between means were tested for significance using the post-hoc Tukey procedure.

RESULTS.

Production of Camelina seeds with different sphingolipid contents. The high expression of the C16 specific Ceramide synthase LOH2 from Arabidopsis in Camelina sativa led to seeds with opposite sphingolipid profile (Supplemental Figure 1). Camelina seeds and meals (cake fraction from seeds) from commercial cultivar Céline (CamC24) presented characteristic sphingolipid profile with high levels of $\mathrm{NH}_{2} \mathrm{GIPC}$ almost exclusively with very long chain $\mathrm{FA}$ (C24). Conversely, the $\mathrm{LOH} 2$ expressing line $\mathrm{LOH}_{2}{ }^{\gamma}$ (CamC16) accumulated almost exclusively C16 $\mathrm{NH}_{2}$ GIPC albeit the levels of total sphingolipids remained similar to CamC24. C16 GluCer was also increased and C24 GluCer strongly decreased in CamC16 (Supplemental Table 2). A similar trend was also observed for Cer and hCer but at a much lower scale. The most abundant LCB in seeds were t18:0 and t18:1 in both lines even if $\mathrm{d} 18: 1$ and $\mathrm{d} 18: 0$ were increased in $\mathrm{LOH} 2^{\Upsilon}$ due to the accumulation of $\mathrm{C} 16 \mathrm{NH}_{2}$ GIPC and GluCer .The accumulation

274 of C16 SL had a weak impact on plant fitness with a slight delay of germination and slower early growth rate as well as a lower seed yield and weight for $\mathrm{LOH}_{2}^{\mathrm{Y}}$ (data not shown). 
Body weight and associated parameters. During the 5 wk of MetS induction, all mice gained weight, but to a different extent (Figure 1). After $5 \mathrm{wk}$ on the experimental diets, mice on the HC-Con diet exhibited a higher weight gain $(8.8 \pm 1.2 \mathrm{~g})$ than mice of the NC group, which gained 3.5 $\pm 1.1 \mathrm{~g}$ only (Supplemental Table 3). In both HC-Cam groups, body weight gain, as well as body weight after 2, 3 and 5 weeks on their respective diets, did not differ significantly from the NC group, but were significantly lower than in the HC-Con group (Figure 1 and Supplemental Table 3). Food intake (as kcal/d) tended to parallel body weight, and was the highest in the HC-Con group after $6 \mathrm{~d}$ and $4 \mathrm{wk}$, whereas there was no difference between groups at both times when energy intake was adjusted for body weight (Supplemental Table 3). Apparent digestibility (\% intake of dry matter that was not found in feces) was equivalent after $6 \mathrm{~d}$ or $4 \mathrm{wk}$ on the same experimental diets. After $6 \mathrm{~d}$, it was the lowest in the NC group, intermediary in the HC-Con group and the highest in the HC-CamC24 and HC-CamC16 groups, whereas after 4 wk, it remained the highest in the HC-CamC24 group only (Supplemental Table 3).

Body composition. After 3 wk on the experimental diets, the lean mass was the same in all groups, whereas the fat mass (absolute and relative to body weight) was as expected higher in the three $\mathrm{HC}$ groups than in the NC group, without significant effect of the camelina meals (Table 2). After 5 wk, mice of the HC-Con group were significantly heavier than those of the NC group whereas mice of both HC-Cam groups showed intermediate body weight (Figure 1 and Table 2). Similarly, when compared to the NC group, adiposity (absolute and relative weight of the EAT) was globally increased in the three HC groups, but to a lower extent in the HC-Cam groups. While liver and small intestine weights were similar in all groups, the 
weights of the caecum and the colon, as well as of the caecum content, were significantly lower in the three $\mathrm{HC}$ groups.

Blood and tissue markers associated with the MetS. During an OGTT after 3 weeks on the experimental diets, glucose and insulin plasma concentration increased sharply during 15 min, then returned to fasting values after $120 \mathrm{~min}$ in all groups (Figure 2). When compared to the NC group, the HC-Con group exhibited higher fasting glucose and insulin concentration (tO) and AUC over $120 \mathrm{~min}$, as well as higher HOMA-IR index (Table 3 and Figure 2). Besides, the increase in glucose concentration between t0 and t30 min, which takes into account the difference in fasting glycemia between groups ( $\Delta$ glucose), was twofold higher in the HC-Con group than in the NC group. In both HC-Cam groups, fasting glucose concentration and AUC over 120 min were similar to those of the HC-Con group, and higher than in the NC-Con group, whereas insulin AUC and HOMA did not differ from the NCCon group and were therefore lower than in the HC-group. Interestingly, insulin fasting plasma concentration in HC-CamC16 mice did not differ from the NC mice and was significantly lower than in the HC-Con mice, which was not the case in mice HC-CamC24 mice. In the two HC-Cam groups, $\Delta$ glucose between t30 and t0 of the OGTT was intermediary between NC- and HC-Con groups.

At the end of the experiment, after 5 weeks on the experimental diets, fasting glucose concentrations did not differ from those after 3 weeks, remaining higher in the three $\mathrm{HC}$ groups than in the NC group (Table 3). Fasting triglyceridemia was identical in NC- and HCCon groups, but was surprisingly 2 -fold lower in the 2 HC-Cam groups. Compared to the NCCon group, fasting cholesterolemia was higher in all the HC groups but only significantly in both HC-Cam groups. 
Transcript levels of a few inflammatory and vascular markers were higher in mice fed the

HC diets: Mcp-1 and Pai-1 in the adipose tissue $(P=0.011$ and 0.002 , respectively) and $I I-1 \beta$ in the colon $(P=0.039)$. However, according to the post-hoc Tukey test, and as compared to

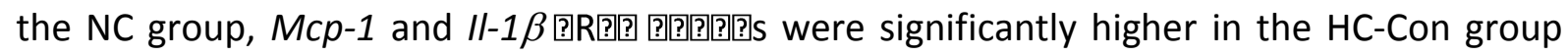
only, and Pai-1 in the HC-Cam groups only (Table 4). Other mRNA levels of inflammatory markers (II-6, II-16, II-10 and Tnf- $\alpha$ in the adipose tissue and II-6, II-10, Tnf- $\alpha$ in the colon) did not differ between groups, neither did those of the tight junction protein encoding genes Tjp1 and Cldn1 in the colon (data not shown).

Colon epithelial barrier and permeability. Measurement of electrical parameters in Ussing chambers was performed on proximal colon (Table 5). There was no difference in the FD4 permeability within the diet groups, which indicated that paracellular pathway of the gut barrier function in the colon was not altered (data not shown). The colon transepithelial voltage $\left(V_{t}\right)$, which is usually negative at the colonocyte luminal side, was more negative in the $3 \mathrm{HC}$ groups than in the control NC group, this effect being significantly less pronounced in the HC-CamC16 group. Conversely, the short-circuit current $\left(I_{s c}\right)$ was higher in the three HC groups, with no difference between them. Trans-epithelial conductance $\left(G_{t}\right)$ in the three HC groups did not differ from that in the NC group, however the HC-CamC16 and the HCCam24 groups showed the highest and lowest values respectively.

SL intake, excretion and tissue profile. Apparent $\mathrm{NH}_{2} \mathrm{GIPC}$ digestibility (Table 6) was calculated after $4 \mathrm{wk}$ of experimental diets, using the in vivo measurement of food intake and fecal excretion and the analysis of complete plant sphingolipidomic profiles of diets (Table 1) and feces (data not shown). Since $\mathrm{NH}_{2}$ GIPC accounted for nearly $80 \%$ of total $\mathrm{SL}$ in 
HC-CamC16 and HC-Cam24 diets, intake and excretion were calculated in this fraction only. Mean individual $\mathrm{NH}_{2} \mathrm{GIPC}$ dietary intake, expressed as absolute amounts, grossly reflected their dietary profile. It was very low in the HC-Con group, much higher in the NC group (over 40 fold increase), and even further increased in both HC-Cam groups by over 80 fold, with no significant difference between the two groups. In contrast, $\mathrm{NH}_{2} \mathrm{GIPC}$ excretion differed markedly between the HC-Cam groups. Excretion rate of $\mathrm{NH}_{2} \mathrm{GIPC}$ in the $\mathrm{HC}$-CamC16 group was 2.5-fold higher than that in the HC-CamC24 group. Consequentely, the apparent digestibility of dietary $\mathrm{NH}_{2}$ GIPC was significantly lower (80\%) in the HC-CamC16 than in the three other groups (87-94\%).

Concentration of the most abundant plant SL ( $\mathrm{NH}_{2} \mathrm{GIPC}$ and GluCer with $\mathrm{C} 16$ and C24 FA) was determined in the jejunum and colon walls (Table 7). Jejunum and colon of the NC group contained similar amount of $\mathrm{C} 24-\mathrm{NH}_{2} \mathrm{GIPC}$ and $\mathrm{C} 24-\mathrm{GluCer}$, while the latter was a minor component of the diet. Jejunum and colon of the HC-Con mice were nearly devoid of phytoSL, as expected from their low level in the HC-Con diet. On the contrary, plant $\mathrm{NH}_{2} \mathrm{GIPC}$ and GluCer were found in the intestine on mice fed with the camelina meals. As expected C24-SL were the most prominent SL in the HC-CamC24 group, while C16-SL was the most abundant in the HC-CamC16 group, with $\mathrm{NH}_{2}$ GIPC being the most abundant $\mathrm{SL}$ in both groups. Tissue content of the various SL species was lower in the colon than in the jejunum, however small levels of plant $\mathrm{NH}_{2}$ GIPC were still present in the colon. Finally, the total concentration of $\mathrm{SL}$ (GluCer $+\mathrm{NH}_{2}$ GIPC) in the intestine of HC-CamC16 mice was approximately 2 -fold higher in the jejunum $(12.5 \mathrm{nmol} / \mathrm{g})$ and in 5 -fold higher in the colon (2.14 nmol/g) than in HC-CamC24 mice $(6.40$ and $0.40 \mathrm{nmol} / \mathrm{g}$ in the jejunum and colon, respectively). Interestingly, while C24-GluCer ratio between colon and jejunum was similar in the two HC-Cam groups (0.38 vs 0.41$)$, this ratio was much lower in the HC-Cam24 group 
372 than in the HC-Cam16 group for $\mathrm{C} 24-\mathrm{NH}_{2} \mathrm{GIPC}(0.05$ vs 0.26$)$ and even lower in the HC-

373 Cam16 group for $\mathrm{C} 16-\mathrm{NH}_{2} \mathrm{GIPC}(0.05$ vs 0.16$)$.

374

375

\section{DISCUSSION.}

Digestive bioavailability of camelina SL. In most in vivo studies aiming to highlight the mechanisms involved in potentially beneficial effects of plant SL at the systemic level, a dramatic gap remains concerning the bioavailability of plant SL when provided in the diet. Both animal and plant SL are hydrolysed into LCB, FA, and the polar head group in the small intestine, then eventually absorbed, reesterified, and secreted into the lymph ${ }^{(37-40)}$. As regards phytoSL, it is needed to document to what extent they are digested then absorbed, in which form they are transported and made available to various tissues, and which molecular species are stored in various body compartments.

To our knowledge, the present study quantifies, for the first time, intestinal digestibility of a major phytoSL ( $\mathrm{NH}_{2}$ GIPC, accounting for nearly $80 \%$ of total $\mathrm{SL}$ in the HC-Cam diets) when provided as a dietary component. Camelina $\mathrm{NH}_{2} \mathrm{GIPC}$ in the two HC-Cam diets exhibited the same LCB profile, and only differed in their FA length (mainly C24 in the CamC24 meal and C16 in the CamC16 meal). Although apparent digestibility of dietary $\mathrm{NH}_{2}$ GIPC was high, it was lower in the HC-CamC16 group, which could be accounted for by a higher fecal excretion. However, the higher $\mathrm{NH}_{2} \mathrm{GIPC}$ content in the gut wall of the $\mathrm{HC}$ Camc16 fed group, suggests some metabolic specificity during reesterification and excretion into the lymph(Table 7). Besides, beyond this demonstration of the $\mathrm{NH}_{2} \mathrm{GIPC}$ availability at the digestive level, $\mathrm{NH}_{2}$ GIPC-containing $\mathrm{SL}$, or their metabolites, have to be sought in other body compartments, this lack of information being a limitation of the present study. 
to exert beneficial effects on some risk factors associated with the MetS, such as altered glucose homeostasis, abnormal lipid profile, and low-grade chronic inflammation. In the present study, we used our mouse model of the early steps of the MetS to explore the effects of dietary plant SL provided by camelina meal in a hypercaloric diet ${ }^{(41)}$. As expected from this model, after 5 wk on a hypercaloric diet rich in saturated FA and sucrose (HC-Con group), mice exhibited (as compared to those on a normocaloric diet, NC-group) an increase in body weight and adiposity (Table 2 and Figure 1), and in fasting glycemia (Table 4). After only $3 \mathrm{wk}$, these alterations were already detectable and were accompanied by higher values of insulinemia and HOMA-IR index (Table 3), and of glucose and insulin postprandial AUC (Figure 2). These findings are consistent with data obtained in mice fed a $\mathrm{HC}$ diet rich in saturated FA ${ }^{(42)}$.

When SL was provided as camelina meal in the HC diet (HC-CamC24 and -C16 groups), body weight gain and adiposity were reduced, but not the lean mass (Figure 1 and Table 2). This specific effect of camelina meals on adiposity was not accounted for by a lower food intake, since it was the same in all groups after $6 \mathrm{~d}$ and 4 wk when normalized for body weight. Whether this effect is due to the presence of SL in the diet is questionable, since no significant effect of phytoSL was reported for body weight, fat mass or body mass index in previous studies ${ }^{(14-17,43,44)}$. In our study, the presence of other components of the camelina meal, such as fibers, may be responsible for a lower nutrient absorption, and subsequent bioavailability, lowering body storage of lipids, either exogenous (dietary) or endogenous (de novo synthesised). However, a specific effect of phytoSL may not be precluded, since a very recent study showed that mice fed a high-fat diet supplemented with milk polar lipids containing $25 \%$ SL gained less weight than mice on the high-fat diet alone ${ }^{(45)}$. 
(Table 3 and Figure 2). These findings are grossly consistent with previous studies using purified SL or LCB in rodent mice models exhibiting features of the MetS or in human subjects with a MetS. Indeed, various SL or LCB decreased triglyceridemia in mice or sand rats on a hypercaloric diet ${ }^{(14,20)}$ whereas phytosphingosine decreased glycemia in subjects with a MetS ${ }^{(15)}$ and improved glucose homeostasis in human subjects with a MetS and 427 various rodent models, ${ }^{(15-19)}$. In contrast, the present study showed no effect on cholesterolemia, which is inconsistent with previous studies that repeatedly reported a decrease in plasma total, LDL, or non-HDL cholesterol in various rodent models and in subjects with a MetS ${ }^{(14,15,17,20)}$. One originality of our short-term study is the demonstration that, when focusing on the onset of the MetS, an early alteration of glucose homeostasis, as may be counteracted by a phytoSL-rich matrix after only 3 weeks on the experimental diets. speculative. First, in response to various SL or LCB, a decrease in the postprandial absorption of dietary triglycerides and cholesterol has been suggested, and would explain the downstream effects on lipid metabolism at the hepatic or plasma level ${ }^{(14,43)}$. Second, gene regulation by SL or LCB, including activation of various PPARs, and resulting in beneficial effects on insulin sensitivity, glucose tolerance and lipid metabolism have been also 440 demonstrated $(17,20,43)$. Finally, it has been recently shown that animal SL may affect gut 441 microbiota in mice in a way that would limit some detrimental effects of HF diets ${ }^{(45,46)}$. All 442 these mechanisms, which remain to be investigated in our model, would contribute to lower adiposity and slower insulin resistance in mice fed the HC-Cam diets (Table 2). 
In response to a diet rich in saturated FA and sucrose, the increased adipose tissue often

445

446

447

448

449

450

451

452

453

454

455

456

457

458

459

460

461

462

463

464

465

466

467

features an inflammatory phenotype ${ }^{(4)}$. In the present study that targeted the initial steps of the MetS, there was no evidence that gene expression of pro-inflammatory cytokines was enhanced in the adipose tissue, despite an increased adiposity, and providing SL-rich camelina meal had no significant effect. Gene expression of two others inflammatory markers, Mcp-1 and Pai-1, was enhanced in response to the HC diet (HC-Con group). Attenuation of Mcp-1 mRNA level may be related to the lower adiposity of mice on both HCCam diets, whereas the reason why the HC-Cam diets aggravated the mRNA level of Pai-1, remains to be investigated.

To our knowledge, the present study, provides the first evidence that a mixture of natural plant SL, essentially in the form of $\mathrm{NH}_{2}$ GIPC, and provided in their original matrix, exerted some beneficial effects during the MetS onset. However, the role of other camelina meal components, such as phospholipids, polyphenols or specific fibers cannot be excluded ${ }^{(47,48)}$.

Effects of the camelina meal on the intestine wall. When compared to the NC group, the HC-Con diet enhanced a few inflammation markers in the colon and the adipose tissue (Table 4). In contrast, in mice fed the camelina meals, mRNA levels of $M c p-1$ in the adipose tissue and of $I I-16$ in the colon did not differ from those in the NC group (Table 4). The role of SL in inflammatory processes is still in debate, but a few studies support the hypothesis that dietary phytoSL (as maize GluCer) or animal SL (as sphingomyelin) alleviate gut inflammation in rodent models ${ }^{(23-28)}$. How plant SL may improve intestinal inflammation remains nonetheless highly speculative. A study using Caco-2 cells suggested that SL may interact with epithelial cells without being absorbed. In these in vitro conditions, plant GluCer remained at the cell surface, but decreased LPS-induced production of inflammatory 
cytokines, maybe by affecting the interactions between LPS and its TLR at the cell surface ${ }^{(28)}$. Similar interactions with non-digested plant SL or their metabolites may contribute in vivo to modulate the inflammatory status of the intestine wall. The intestinal microbiota is likely to contribute to these interactions, since it is able to metabolize animal SL, which would contribute to regulate cytokine production ${ }^{(24,49)}$.

Interestingly, epithelial integrity of the colon was specifically modified by the HC-CamC16 diet, as demonstrated by its effects on transepithelial voltage $\left(V_{t}\right)$ and epithelial conductance $\left(G_{t}\right)$ (Table 5). $V_{t}$ describes the unidirectional transport of sodium from the luminal to the serosal side of the epithelium. This potential difference is usually negative at the colonocyte luminal side, and was even more negative with $\mathrm{HC}$ diets. This effect of HC-diets reflects an increase in the driving force of the colonocytes to allow the sodium, chloride and water absorption from the colon lumen, and therefore a loss of permeability. This decrease in $V_{t}$ may be related to the high fat content of the diet, known to alter electrical parameters of transcellular barrier function ${ }^{(42,50,51)}$. This damage was attenuated in mice given the diet containing camelina SL rich in C16 FA (HC-CamC16). $V_{t}$ increase in HC-Camc16 mice was also associated with higher epithelial conductance $\left(G_{t}\right)$ which was not due to a loss of epithelial permeability, at least via the paracellular pathway, because it was not accompanied by an increase in the apical-to-basal flux of the paracellular marker FD4 in any group. The absence of dietary effects on the gene expression of two tight junction proteins, claudin 1 (Cldn1) and zonula occludens (Tjp1), confirms that the paracellular permeability was not affected by any of the HC diets. Rather, we suggest that, in the colon of the HC-CamC16 mice, this increased $G_{t}$ may reflect a compensatory mechanism that counteracts the increase of actively transported ions (as evidenced by the higher short-circuit current $-I_{c^{-}}$in all $\mathrm{HC}$ groups) by increasing passive movement of ions. This would explain the lower value of $V_{t}$ in the HC- 
CamC16 group. Nevertheless, further investigations would be needed to determine the precise mechanisms involved in the action of camelina SL (native or digested products) on activity and/or expression of colon transporters and exchangers that ensured colon barrier integrity and flux. Yet, it can be concluded from the present study than differences in the FA profile of dietary plant SL, and particularly the enrichment of C16 FA in the experimental $\mathrm{LOH}_{2}^{\mathrm{Y}}$ line (to the detriment of C24 FA in the commercial Céline cultivar) modulate the deleterious effects of a high-fat diet on colon epithelial barrier function, and more specifically on transepithelial permeability.

reducing adiposity and insulin resistance. Involved mechanisms at the intestinal and systemic levels remain mostly speculative at this initial stage, but it may be hypothesized that some of the effects observed, including on the adipose tissue and blood parameters, results from an impact of phytoSL or their metabolites at the intestinal level. Moreover, some of these effects are modulated by the FA length of the SL, since they are sometimes more pronounced in presence of $\mathrm{C} 16-\mathrm{NH}_{2} \mathrm{GIPC}$. More researchs are required to uncover the importance of FA length in the interactions between phytoSL, the intestinal wall, and systemic effects. In this context, interactions of phytoSL and their metabolites with the microbiota may be a promising avenue of investigation.

\section{Acknowledgements}

The authors acknowledge the valuable contribution of Célia Carbonne, MSc student in UMR Physiologie de la Nutrition et du Comportement Alimentaire (PNCA), who contributed to the running of the study, and of Morgane Dufay (UMR PNCA) for animal care and help with 
dissection and sampling. They thank Ophélie Dhumez (UMR Modélisation systémique

517

518

519

520

521

522

523

524

525

526

527

528

529

530

531

532

533

534

535

536

537

538

539

Appliquée aux Ruminants) for the determination of nutrient composition of the camelina meals.

Funding: This study was funded by Scientific direction and valorisation of AgroParisTech (2015 incitative call, NUTRICAM project). It has benefited from a French State grant (LabEx Saclay Plant Sciences-SPS, ref. ANR-10-LABX-0040-SPS), managed by the French National Research Agency under an "Investments for the Future" program (ref. ANR-11-IDEX-000302).

\section{Supporting information.}

Supplemental Table 1. Composition and nutritional values of the experimental diets.

Supplemental Table 2. SL composition of the camelina meals (nmol/g)

Supplemental Table 3. Body weight gain and food intake

Supplemental Figure 1. $\mathrm{NH}_{2}$ GIPCS and GICers profiles in Camelina sativa seeds from the commercial Céline cultivar (CamC24) and from the $\mathrm{LOH}_{2}^{\mathrm{Y}}$ line (CamC16).

\section{References.}

1. Alberti, K. G.; Eckel, R. H.; Grundy, S. M.; Zimmet, P. Z.; Cleeman, J. I.; Donato, K. A.; Fruchart, J. C.; James, W. P.; Loria, C. M.; Smith, S. C., Jr., Harmonizing the metabolic syndrome: a joint interim statement of the International Diabetes Federation Task Force on Epidemiology and Prevention; National Heart, Lung, and Blood Institute; American Heart Association; World Heart Federation; International Atherosclerosis Society; and International Association for the Study of Obesity. Circulation 2009, 120, 1640-5. 
541 Pelt, R. E.; Wang, H.; Eckel, R. H., The metabolic syndrome. Endocr Rev 2008, 29, 777-822.

542 3. Araujo, J. R.; Tomas, J.; Brenner, C.; Sansonetti, P. J., Impact of high-fat diet on the intestinal microbiota and small intestinal physiology before and after the onset of obesity. Biochimie 2017, $141,97-106$.

4. Dandona, P.; Ghanim, H.; Chaudhuri, A.; Dhindsa, S.; Kim, S. S., Macronutrient intake induces oxidative and inflammatory stress: potential relevance to atherosclerosis and insulin resistance. Experimental \& molecular medicine 2010, 42, 245-53.

5. Tremaroli, V.; Backhed, F., Functional interactions between the gut microbiota and host metabolism. Nature 2012, 489, 242-9.

6. Ji, Y.; Sakata, Y.; Tso, P., Nutrient-induced inflammation in the intestine. Curr Opin Clin Nutr Metab Care 2011, 14, 315-21.

553 Changes in gut microbiota control metabolic endotoxemia-induced inflammation in high-fat diet554 induced obesity and diabetes in mice. Diabetes 2008, 57, 1470-81. 8. Minihane, A. M.; Vinoy, S.; Russell, W. R.; Baka, A.; Roche, H. M.; Tuohy, K. M.; Teeling, J. L.; Blaak, E. E.; Fenech, M.; Vauzour, D.; McArdle, H. J.; Kremer, B. H.; Sterkman, L.; Vafeiadou, K.; Benedetti, M. M.; Williams, C. M.; Calder, P. C., Low-grade inflammation, diet composition and health: current research evidence and its translation. Br J Nutr 2015, 114, 999-1012. microbiota in health and disease: an overview focused on metabolic inflammation. Beneficial microbes 2016, 7, 181-94. connection and beyond. Frontiers in plant science 2012, 3, 68.

564 11. Lipina, C.; Hundal, H. S., Sphingolipids: agents provocateurs in the pathogenesis of insulin resistance. Diabetologia 2011, 54, 1596-607. 

196-205.

13. Park, J. W.; Park, W. J.; Kuperman, Y.; Boura-Halfon, S.; Pewzner-Jung, Y.; Futerman, A. H., Ablation of very long acyl chain sphingolipids causes hepatic insulin resistance in mice due to altered detergent-resistant membranes. Hepatology 2013, 57, 525-32. J.; Havekes, L. M.; Nieuwenhuizen, W. F., Dietary sphingolipids lower plasma cholesterol and triacylglycerol and prevent liver steatosis in APOE*3Leiden mice. Am J Clin Nutr 2006, 84, 312-21. J. A.; Jazet, I. M., The effect of dietary phytosphingosine on cholesterol levels and insulin sensitivity in subjects with the metabolic syndrome. Eur J Clin Nutr 2010, 64, 419-23.

16. Murakami, I.; Mitsutake, S.; Kobayashi, N.; Matsuda, J.; Suzuki, A.; Shigyo, T.; Igarashi, Y., 578 Improved high-fat diet-induced glucose intolerance by an oral administration of phytosphingosine. 579 Bioscience, biotechnology, and biochemistry 2013, 77, 194-7.

17. Yunoki, K.; Renaguli, M.; Kinoshita, M.; Matsuyama, H.; Mawatari, S.; Fujino, T.; Kodama, Y.; Sugiyama, M.; Ohnishi, M., Dietary sphingolipids ameliorate disorders of lipid metabolism in Zucker fatty rats. J Agric Food Chem 2010, 58, 7030-5. Y., Beta-glycosphingolipids improve glucose intolerance and hepatic steatosis of the Cohen diabetic rat. Am J Physiol Endocrinol Metab 2009, 296, E72-8.

19. Lalazar, G.; Zigmond, E.; Weksler-Zangen, S.; Ben Ya'acov, A.; Sklair Levy, M.; Hemed, N.; Raz, I.; Ilan, Y., Oral Administration of beta-Glucosylceramide for the Treatment of Insulin Resistance and Nonalcoholic Steatohepatitis: Results of a Double-Blind, Placebo-Controlled Trial. J Med Food 2017. 
591

592

593

594

595

596

597

598

599

600

601

602

603

604

605

606

607

608

609

610

611

612

613

614

615

616

ameliorated non-alcoholic steatohepatitis in the Psammomys obesus model. Journal of inflammation research 2014, 7, 151-8.

21. Norris, G. H.; Blesso, C. N., Dietary sphingolipids: potential for management of dyslipidemia and nonalcoholic fatty liver disease. Nutr Rev 2017, 75, 274-285.

22. Zhang, W.; Moritoki, Y.; Tsuneyama, K.; Yang, G. X.; Ilan, Y.; Lian, Z. X.; Gershwin, M. E., Betaglucosylceramide ameliorates liver inflammation in murine autoimmune cholangitis. Clinical and experimental immunology 2009, 157, 359-64.

23. Arai, K.; Mizobuchi, Y.; Tokuji, Y.; Aida, K.; Yamashita, S.; Ohnishi, M.; Kinoshita, M., Effects of Dietary Plant-Origin Glucosylceramide on Bowel Inflammation in DSS-Treated Mice. J Oleo Sci 2015, $64,737-42$.

24. Bryan, P. F.; Karla, C.; Edgar Alejandro, M. T.; Sara Elva, E. P.; Gemma, F.; Luz, C., Sphingolipids as Mediators in the Crosstalk between Microbiota and Intestinal Cells: Implications for Inflammatory Bowel Disease. Mediators of inflammation 2016, 2016, 9890141.

25. Camp, E. R.; Patterson, L. D.; Kester, M.; Voelkel-Johnson, C., Therapeutic implications of bioactive sphingolipids: A focus on colorectal cancer. Cancer biology \& therapy 2017, 18, 640-650.

26. Duan, J.; Sugawara, T.; Sakai, S.; Aida, K.; Hirata, T., Oral glucosylceramide reduces 2,4dinitrofluorobenzene induced inflammatory response in mice by reducing TNF-alpha levels and leukocyte infiltration. Lipids 2011, 46, 505-12.

27. Mazzei, J. C.; Zhou, H.; Brayfield, B. P.; Hontecillas, R.; Bassaganya-Riera, J.; Schmelz, E. M., Suppression of intestinal inflammation and inflammation-driven colon cancer in mice by dietary sphingomyelin: importance of peroxisome proliferator-activated receptor gamma expression. J Nutr Biochem 2011, 22, 1160-71.

28. Yamashita, S.; Sakurai, R.; Hishiki, K.; Aida, K.; Kinoshita, M., Effects of Dietary Plant-origin Glucosylceramide on Colon Cytokine Contents in DMH-treated Mice. J Oleo Sci 2017, 66, 157-160.

29. Tellier, F.; Maia-Grondard, A.; Schmitz-Afonso, I.; Faure, J. D., Comparative plant sphingolipidomic reveals specific lipids in seeds and oil. Phytochemistry 2014, 103, 50-8. 
30. Julie-Galau, S.; Bellec, Y.; Faure, J. D.; Tepfer, M., Evaluation of the potential for interspecific hybridization between Camelina sativa and related wild Brassicaceae in anticipation of field trials of GM camelina. Transgenic research 2014, 23, 67-74.

31. Morineau, C.; Bellec, Y.; Tellier, F.; Gissot, L.; Kelemen, Z.; Nogue, F.; Faure, J. D., Selective gene dosage by CRISPR-Cas9 genome editing in hexaploid Camelina sativa. Plant biotechnology journal 2017, 15, 729-739.

32. de Andrade, P. V.; Schmidely, P., Effect of duodenal infusion of trans10,cis12-CLA on milk performance and milk fatty acid profile in dairy goats fed high or low concentrate diet in combination with rolled canola seed. Reprod Nutr Dev 2006, 46, 31-48.

33. Beaumont, M.; Andriamihaja, M.; Armand, L.; Grauso, M.; Jaffrezic, F.; Laloe, D.; Moroldo, M.; Davila, A. M.; Tome, D.; Blachier, F.; Lan, A., Epithelial response to a high-protein diet in rat colon. BMC Genomics 2017, 18, 116.

34. Fossati, P.; Prencipe, L., Serum triglycerides determined colorimetrically with an enzyme that produces hydrogen peroxide. Clin Chem 1982, 28, 2077-80.

35. Takayama, M.; Itoh, S.; Nagasaki, T.; Tanimizu, I., A new enzymatic method for determination of serum choline-containing phospholipids. Clin Chim Acta 1977, 79, 93-8.

36. Markham, J. E.; Jaworski, J. G., Rapid measurement of sphingolipids from Arabidopsis thaliana by reversed-phase high-performance liquid chromatography coupled to electrospray ionization tandem mass spectrometry. Rapid communications in mass spectrometry : RCM 2007, 21, $1304-14$

37. Fujii, A.; Manabe, Y.; Aida, K.; Tsuduki, T.; Hirata, T.; Sugawara, T., Selective Absorption of Dietary Sphingoid Bases from the Intestine via Efflux by P-Glycoprotein in Rats. J Nutr Sci Vitaminol (Tokyo) 2017, 63, 44-50.

38. Ishikawa, J.; Takada, S.; Hashizume, K.; Takagi, Y.; Hotta, M.; Masukawa, Y.; Kitahara, T.; Mizutani, Y.; Igarashi, Y., Dietary glucosylceramide is absorbed into the lymph and increases levels of epidermal sphingolipids. Journal of dermatological science 2009, 56, 220-2. 
39. Sugawara, T.; Kinoshita, M.; Ohnishi, M.; Nagata, J.; Saito, M., Digestion of maize sphingolipids in rats and uptake of sphingadienine by Caco-2 cells. J Nutr 2003, 133, 2777-82.

40. Sugawara, T.; Tsuduki, T.; Yano, S.; Hirose, M.; Duan, J.; Aida, K.; Ikeda, I.; Hirata, T., Intestinal absorption of dietary maize glucosylceramide in lymphatic duct cannulated rats. J Lipid Res 2010, 51, 1761-9.

41. Hermier, D.; Guelzim, N.; Martin, P. G.; Huneau, J. F.; Mathe, V.; Quignard-Boulange, A.; Lasserre, F.; Mariotti, F., NO synthesis from arginine is favored by alpha-linolenic acid in mice fed a high-fat diet. Amino Acids 2016, 48, 2157-68.

42. Lam, Y. Y.; Ha, C. W.; Hoffmann, J. M.; Oscarsson, J.; Dinudom, A.; Mather, T. J.; Cook, D. I.; Hunt, N. H.; Caterson, I. D.; Holmes, A. J.; Storlien, L. H., Effects of dietary fat profile on gut permeability and microbiota and their relationships with metabolic changes in mice. Obesity (Silver Spring) 2015, 23, 1429-39.

43. Chung, R. W.; Kamili, A.; Tandy, S.; Weir, J. M.; Gaire, R.; Wong, G.; Meikle, P. J.; Cohn, J. S.; Rye, K. A., Dietary sphingomyelin lowers hepatic lipid levels and inhibits intestinal cholesterol absorption in high-fat-fed mice. PLoS One 2013, 8, e55949.

44. Lalazar, G.; Zigmond, E.; Weksler-Zangen, S.; Ya'acov, A. B.; Levy, M. S.; Hemed, N.; Raz, I.; Ilan, Y., Oral Administration of beta-Glucosylceramide for the Treatment of Insulin Resistance and Nonalcoholic Steatohepatitis: Results of a Double-Blind, Placebo-Controlled Trial. J Med Food 2017, $20,458-464$.

45. Milard, M.; Laugerette, F.; Durand, A.; Buisson, C.; Meugnier, E.; Loizon, E.; Louche-Pelissier, C.; Sauvinet, V.; Garnier, L.; Viel, S.; Bertrand, K.; Joffre, F.; Cheillan, D.; Humbert, L.; Rainteau, D.; Plaisancie, P.; Bindels, L. B.; Neyrinck, A. M.; Delzenne, N. M.; Michalski, M. C., Milk Polar Lipids in a High-Fat Diet Can Prevent Body Weight Gain: Modulated Abundance of Gut Bacteria in Relation with Fecal Loss of Specific Fatty Acids. Mol Nutr Food Res 2019, 63, e1801078.

46. Norris, G. H.; Jiang, C.; Ryan, J.; Porter, C. M.; Blesso, C. N., Milk sphingomyelin improves lipid metabolism and alters gut microbiota in high fat diet-fed mice. J Nutr Biochem 2016, 30, 93-101. 
669 47. Chaturvedi, S.; Bhattacharya, A.; Khare, S. K.; Kaushik, G., Camelina sativa: An Emerging 670 Biofuel Crop. In Handbook of Environmental Materials Management, Hussain, C. M., Ed. Springer 671 International Publishing: Cham, 2018; pp 1-38.

672 48. Smit, M. N.; Beltranena, E., Effects of feeding camelina cake to weaned pigs on safety, 673 growth performance, and fatty acid composition of pork. Journal of animal science 2017, 95, 24966742508.

675 49. Norris, G. H.; Blesso, C. N., Dietary and Endogenous Sphingolipid Metabolism in Chronic 676 Inflammation. Nutrients 2017, 9.

677 50. Muller, V. M.; Zietek, T.; Rohm, F.; Fiamoncini, J.; Lagkouvardos, I.; Haller, D.; Clavel, T.; 678 Daniel, H., Gut barrier impairment by high-fat diet in mice depends on housing conditions. Mol Nutr 679 Food Res 2016, 60, 897-908.

680 51. Tomas, J.; Mulet, C.; Saffarian, A.; Cavin, J. B.; Ducroc, R.; Regnault, B.; Kun Tan, C.; Duszka, 681 K.; Burcelin, R.; Wahli, W.; Sansonetti, P. J.; Pedron, T., High-fat diet modifies the PPAR-gamma 682 pathway leading to disruption of microbial and physiological ecosystem in murine small intestine. 683 Proc Natl Acad Sci U S A 2016, 113, E5934-E5943.

684 
Table 1. SL composition of the experimental diets ( $\mathrm{nmol} / \mathrm{g}$ ).

688

689

690

691

692

693

694

695

696

697

698

699

700

701

702

703

704

705

706

707

708

709

710

\begin{tabular}{lcccc}
\hline & NC & HC-Con & HC-CamC24 & HC-CamC16 \\
\hline Total Cer & 125 & 54 & 61 & 70
\end{tabular}

C16-Cer

11.4

8.36

9.39

14.7

C24-Cer

43.7

14.3

16.6

17.5

Total hCer

107

34

44

53

C16-hCer

4.99

5.61

5.84

10.9

C24-hCer

45.2

13.0

18.1

19.7

Total GluCer

20

0.44

10.6

7.6

C16-GluCer

6.26

0.14

1.53

4.3

C24-GluCer

8.30

0.20

7.08

2.4

Total $\mathrm{NH}_{2} \mathrm{GIPC}$

222

5.31

444

463

C16- $\mathrm{NH}_{2} \mathrm{GIPC}$

0.82

0.38

6.71

421

C24- $\mathrm{NH}_{2} \mathrm{GIPC}$

98.9

2.61

363

33

Total SL

473

94.0

560

593

C16-SL

23.4

14.3

23.5

450

C24-SL

194

30.0

404

72.6

Total $\mathrm{NH}_{2} \mathrm{GIPC}$

(\% of total SL)

46.9

5.6

79.3

78.1

C16- $\mathrm{NH}_{2} \mathrm{GIPC}$

(\% of total $\mathrm{NH}_{2}$ GIPC)

$0.37 \quad 7.16$

1.51

90.9

C24-NH ${ }_{2}$ GIPC

(\% of total $\mathrm{NH}_{2}$ GIPC)

49.2

81.8

7.1

$\begin{array}{llll}44.5 & 49.2 & 81.8 & 7.1\end{array}$

NC, normo-caloric; HC, hyper-caloric; Con, control; CamC24, camelina meal C24 (from the commercial Céline cultivar rich in C24 fatty acids); CamC16, camelina meal C16 (from the experimental LOH2 cultivar rich in C16 fatty acids); hCer, hydroxyceramide; GluCer, glucosylceramide; $\mathrm{NH}_{2} \mathrm{GIPC}$, aminoglycosyl-inositol-phosphoryl-ceramide. 


\begin{tabular}{lccccc}
\hline & NC & HC-Con & HC-CamC24 & HC-CamC16 & P ANOVA \\
\hline $\begin{array}{l}\text { After 3 weeks } \\
\text { Body weight } \\
\text { (fed state, g) } \\
\text { Lean body mass } \\
\text { (g) }\end{array}$ & $25.6 \pm 2.0^{\mathrm{a}}$ & $29.9 \pm 2.4^{\mathrm{b}}$ & $27.1 \pm 1.4^{\mathrm{a}}$ & $27.0 \pm 1.0^{\mathrm{a}}$ & 0.0013 \\
$\begin{array}{l}\text { Fat body mass } \\
\text { (g) }\end{array}$ & $21.2 \pm 1.5^{\mathrm{a}}$ & $21.0 \pm 0.9^{\mathrm{a}}$ & $20.0 \pm 1.1^{\mathrm{a}}$ & $20.5 \pm 0.7^{\mathrm{a}}$ & 0.1086 \\
$\begin{array}{l}\text { Fat body mass } \\
\text { (\% body weight) }\end{array}$ & $4.28 \pm 0.79^{\mathrm{a}}$ & $8.31 \pm 1.92^{\mathrm{c}}$ & $6.69 \pm 1.72^{\mathrm{bc}}$ & $6.19 \pm 1.07^{\mathrm{ab}}$ & 0.0006 \\
\hline $\begin{array}{l}\text { After 5 weeks } \\
\text { Body weight } \\
\text { (fasted state, g) }\end{array}$ & $16.7 \pm 2.4^{\mathrm{a}}$ & $28.1 \pm 4.8^{\mathrm{b}}$ & $24.9 \pm 5.2^{\mathrm{b}}$ & $23.1 \pm 3.2^{\mathrm{b}}$ & 0.0004 \\
$\begin{array}{l}\text { EAT } \\
\text { (mg) }\end{array}$ & $26.7 \pm 2.5^{\mathrm{a}}$ & $31.5 \pm 4.1^{\mathrm{b}}$ & $28.6 \pm 0.5^{\mathrm{ab}}$ & $28.6 \pm 1.3^{\mathrm{ab}}$ & 0.0148 \\
$\begin{array}{l}\text { EAT } \\
\text { (\% body weight) }\end{array}$ & $558 \pm 117^{\mathrm{a}}$ & $1446 \pm 520^{\mathrm{b}}$ & $911 \pm 199^{\mathrm{a}}$ & $946 \pm 186^{\mathrm{a}}$ & 0.0003 \\
$\begin{array}{l}\text { Liver } \\
\text { (g) }\end{array}$ & $2.08 \pm 0.36^{\mathrm{a}}$ & $4.48 \pm 1.18^{\mathrm{c}}$ & $3.19 \pm 0.60^{\mathrm{b}}$ & $3.29 \pm 0.52^{\mathrm{b}}$ & 0.0002 \\
$\begin{array}{l}\text { Small intestine } \\
\text { (mg) }\end{array}$ & $1.18 \pm 0.15^{\mathrm{a}}$ & $1.16 \pm 0.16^{\mathrm{a}}$ & $1.07 \pm 0.20^{\mathrm{a}}$ & $1.05 \pm 0.17^{\mathrm{a}}$ & 0.4780 \\
$\begin{array}{l}\text { Caecum } \\
\text { (mg) }\end{array}$ & $947 \pm 96^{\mathrm{a}}$ & $836 \pm 91^{\mathrm{a}}$ & $830 \pm 60^{\mathrm{a}}$ & $862 \pm 84^{\mathrm{a}}$ & 0.0546 \\
$\begin{array}{l}\text { Caecum content } \\
\text { (mg) } \\
\text { Colon } \\
\text { (mg) }\end{array}$ & $109 \pm 23^{\mathrm{a}}$ & $58 \pm 33^{\mathrm{b}}$ & $69 \pm 18^{\mathrm{b}}$ & $67 \pm 13^{\mathrm{b}}$ & 0.0002 \\
$\begin{array}{l}\text { Colon content } \\
\text { (mg) }\end{array}$ & $301 \pm 76^{\mathrm{a}}$ & $157 \pm 41^{\mathrm{b}}$ & $164 \pm 53^{\mathrm{b}}$ & $185 \pm 31^{\mathrm{b}}$ & $<0.0001$ \\
\hline & $193 \pm 19^{\mathrm{a}}$ & $139 \pm 25^{\mathrm{b}}$ & $132 \pm 15^{\mathrm{b}}$ & $131 \pm 29^{\mathrm{b}}$ & $<0.0001$ \\
& $115 \pm 17^{\mathrm{a}}$ & $79 \pm 21^{\mathrm{a}}$ & $91 \pm 28^{\mathrm{a}}$ & $101 \pm 34^{\mathrm{a}}$ & 0.0968 \\
\hline & & & & & \\
\hline
\end{tabular}

712 Values are means \pm standard deviations for 6 and 9 mice in the NC and the three HC-groups,

713 respectively. Mean values within a row, not sharing a same superscript letter, were

714 significantly different at $P<0.05$.

715 NC, normo-caloric; HC, hyper-caloric; Con, control; CamC24, camelina meal C24 (from the 716 commercial Céline cultivar rich in C24 fatty acids); CamC16, camelina meal C16 (from the 717 experimental LOH2 cultivar rich in C16 fatty acids); EAT, epididymal adipose tissue. 

weeks on the experimental diets.

\begin{tabular}{lccccc}
\hline & NC & HC-Con & HC-CamC24 & HC-CamC16 & P ANOVA \\
\hline 3 weeks & & & & & \\
Glucose t0 $(\mathrm{g} / \mathrm{L})$ & $1.22 \pm 0.10^{\mathrm{a}}$ & $1.59 \pm 0.13^{\mathrm{b}}$ & $1.52 \pm 0.14^{\mathrm{b}}$ & $1.51 \pm 0.13^{\mathrm{b}}$ & $<0.0001$ \\
Insulin t0 $(\mu \mathrm{g} / \mathrm{L})$ & $0.67 \pm 0.33^{\mathrm{a}}$ & $1.37 \pm 0.38^{\mathrm{b}}$ & $0.90 \pm 0.42^{\mathrm{ab}}$ & $0.78 \pm 0.33^{\mathrm{a}}$ & 0.0035 \\
HOMA-IR index & $5.63 \pm 2.48^{\mathrm{a}}$ & $15.60 \pm 5.03^{\mathrm{b}}$ & $9.73 \pm 4.36^{\mathrm{a}}$ & $8.33 \pm 3.54^{\mathrm{a}}$ & 0.0004 \\
\hline glucose & $0.59 \pm 0.17^{\mathrm{a}}$ & $1.41 \pm 0.50^{\mathrm{b}}$ & $1.22 \pm 0.78^{\mathrm{ab}}$ & $0.91 \pm 0.32^{\mathrm{ab}}$ & 0.0261 \\
(t30-t0 g/L) & & & & & \\
\hline 5 weeks & & & & & \\
Glucose $(\mathrm{g} / \mathrm{L})$ & $1.18 \pm 0.17^{\mathrm{a}}$ & $1.60 \pm 0.17^{\mathrm{b}}$ & $1.58 \pm 0.14^{\mathrm{b}}$ & $1.55 \pm 0.14^{\mathrm{b}}$ & $<0.0001$ \\
Triglyceride $(\mathrm{g} / \mathrm{L})$ & $0.69 \pm 0.18^{\mathrm{a}}$ & $0.60 \pm 10^{\mathrm{a}}$ & $0.35 \pm 0.04^{\mathrm{b}}$ & $0.38 \pm 0.09^{\mathrm{b}}$ & $<0.0001$ \\
Cholesterol $(\mathrm{g} / \mathrm{L})$ & $1.01 \pm 0.18^{\mathrm{a}}$ & $1.55 \pm 0.47^{\mathrm{ab}}$ & $1.73 \pm 0.32^{\mathrm{b}}$ & $1.74 \pm 0.19^{\mathrm{b}}$ & 0.0088 \\
\hline
\end{tabular}

721 Values are means \pm standard deviations for 6 and 9 mice in the NC and the three HC-groups, 722 respectively. Mean values within a row, not sharing a same superscript letter, were 723 significantly different at $P<0.05$.

724 NC, normo-caloric; HC, hyper-caloric; Con, control; CamC24, camelina meal C24 (from the 725 commercial Céline cultivar rich in C24 fatty acids); CamC16, camelina meal C16 (from the 726 experimental LOH2 cultivar rich in C16 fatty acids). 
Table 4. Relative gene expression level of some markers of low-grade inflammation.

730

\begin{tabular}{lccccc}
\hline & NC & HC-Con & HC-CamC24 & HC-CamC16 & P ANOVA \\
\hline EAT & & & & & \\
Mcp-1 & $1.19 \pm 0.72^{\mathrm{a}}$ & $3.55 \pm 2.07^{\mathrm{b}}$ & $2.79 \pm 1.10^{\mathrm{ab}}$ & $2.08 \pm 0.77^{\mathrm{ab}}$ & 0.0168 \\
Pai-1 & $1.24 \pm 0.81^{\mathrm{a}}$ & $2.67 \pm 1.02^{\mathrm{ab}}$ & $4.12 \pm 1.64^{\mathrm{b}}$ & $3.17 \pm 1.28^{\mathrm{b}}$ & 0.0021 \\
Colon & & & & & \\
II-16 & $1.03 \pm 0.25^{\mathrm{a}}$ & $2.03 \pm 1.02^{\mathrm{b}}$ & $1.60 \pm 0.39^{\mathrm{ab}}$ & $1.58 \pm 0.44^{\mathrm{ab}}$ & 0.0707 \\
\hline
\end{tabular}

731

732 Values are means \pm standard deviations for 6 and 8-9 mice in the NC and the three HC-

733 groups, respectively. They were calculated according to the $2^{-\Delta \Delta C t}$, where $\Delta C t=(\mathrm{Ct}$ target

734 gene - Ct HPRT) normalized to the NC group. Mean values within a row, not sharing a same

735 superscript letter, were significantly different at $P<0.05$.

736 NC, normo-caloric; HC, hyper-caloric; Con, control; CamC24, camelina meal C24 (from the

737 commercial Céline cultivar rich in C24 fatty acids); CamC16, camelina meal C16 (from the experimental $\mathrm{LOH} 2$ cultivar rich in $\mathrm{C} 16$ fatty acids). 
Table 5. Electrical measurement of colon epithelium parameters in Ussing chambers.

741

\begin{tabular}{lccccc}
\hline & NC & HC-Con & HC-CamC24 & HC-CamC16 & P ANOVA \\
\hline$V_{t}(\mathrm{mV})$ & $-2.78 \pm 0.15^{\mathrm{a}}$ & $-8.45 \pm 0.83^{\mathrm{b}}$ & $-9.08 \pm 1.32^{\mathrm{b}}$ & $-5.90 \pm 1.30^{\mathrm{c}}$ & $<0.0001$ \\
$I_{s c}\left(\mu \mathrm{A} / \mathrm{cm}^{2}\right)$ & $59 \pm 10^{\mathrm{a}}$ & $166 \pm 17^{\mathrm{b}}$ & $149 \pm 14^{\mathrm{b}}$ & $142 \pm 3^{\mathrm{b}}$ & $<0.0001$ \\
$G_{t}\left(\mathrm{mS} / \mathrm{cm}^{2}\right)$ & $16.8 \pm 2.2^{\mathrm{ab}}$ & $16.5 \pm 1.8^{\mathrm{ab}}$ & $14.0 \pm 2.4^{\mathrm{a}}$ & $20.1 \pm 3.3^{\mathrm{b}}$ & 0.0396 \\
\hline
\end{tabular}

742

743

Measures were acquired after 45-minutes epithelium equilibration in recording buffer. $V_{t}$

744 trans-epithelial voltage; $I_{s c}$ short-circuit current; $G_{t}$ trans-epithelial electrical conductance.

745 Values are means \pm standard deviations for 3-4 mice in each group.

746 Mean values within a row, not sharing a same superscript letter, were significantly different

$747 \quad$ at $P<0.05$.

748 NC, normo-caloric; HC, hyper-caloric; Con, control; CamC24, camelina meal C24 (from the 749 commercial Céline cultivar rich in C24 fatty acids); CamC16, camelina meal C16 (from the 750 experimental LOH2 cultivar rich in C16 fatty acids). 

experimental diets.

\begin{tabular}{|c|c|c|c|c|c|}
\hline & NC & HC-Con & HC-CamC24 & HC-CamC16 & $P$ ANOVA \\
\hline $\begin{array}{l}\mathrm{NH}_{2} \mathrm{GIPC} \text { Intake } \\
(\mathrm{nmol} / \mathrm{d})\end{array}$ & $784 \pm 36^{b}$ & $17.7 \pm 1.5^{c}$ & $1209 \pm 186^{a}$ & $1358 \pm 195^{a}$ & $<0.0001$ \\
\hline $\begin{array}{l}\mathrm{NH}_{2-} \text { GIPC Excretion } \\
(\mathrm{nmol} / \mathrm{d})\end{array}$ & $43.7 \pm 10.5^{c}$ & $2.45 \pm 0.84^{c}$ & $113 \pm 33^{b}$ & $278 \pm 48^{a}$ & $<0.0001$ \\
\hline $\begin{array}{l}\mathrm{NH}_{2} \text { GIPC Excretion } \\
\text { (intake \%) }\end{array}$ & $5.74 \pm 1.49^{c}$ & $13.73 \pm 4.30^{b}$ & $9.40 \pm 2.58^{c}$ & $20.33 \pm 2.61^{a}$ & $<0.0001$ \\
\hline $\begin{array}{l}\text { Apparent digestibility } \\
\text { (intake \%) }\end{array}$ & $94.3 \pm 1.5^{a}$ & $86.3 \pm 2.6^{b}$ & $90.6+2.6^{\mathrm{ab}}$ & $79.7 \pm 2.6^{c}$ & $<0.0001$ \\
\hline
\end{tabular}

754 Values are means \pm standard deviations for 6 and 9 mice in the NC and the three HC-groups, 755 respectively. Mean values within a row, not sharing a same superscript letter, were 756 significantly different at $P<0.05$.

757 NC, normo-caloric; HC, hyper-caloric; Con, control; CamC24, camelina meal C24 (from the 758 commercial Céline cultivar rich in C24 fatty acids); CamC16, camelina meal C16 (from the 759 experimental LOH2 cultivar rich in C16 fatty acids). 


\begin{tabular}{|c|c|c|c|c|c|}
\hline & NC & HC-Con & HC-CamC24 & HC-CamC16 & $P$ ANOVA \\
\hline \multicolumn{6}{|l|}{ Jejunum } \\
\hline C16 GluCer & $0.025 \pm 0.021^{\mathrm{ab}}$ & nd & $0.009 \pm 0.008^{b}$ & $0.027 \pm 0.016^{\mathrm{a}}$ & 0.0004 \\
\hline C24-GluCer & $0.499 \pm 0.295^{a}$ & $0.108 \pm 0.040^{b}$ & $0.333 \pm 0.150^{\mathrm{a}}$ & $0.289 \pm 0.108^{a b}$ & 0.0006 \\
\hline C16-NH ${ }_{2}$ GIPC & nd & nd & $0.248 \pm 0.122^{b}$ & $11.683 \pm 2.085^{a}$ & $<0.0001$ \\
\hline $\mathrm{C} 24-\mathrm{NH}_{2} \mathrm{GIPC}$ & $0.671 \pm 0.231^{b}$ & nd & $5.799 \pm 1.609^{a}$ & $0.481 \pm 0.138^{b}$ & $<0.0001$ \\
\hline \multicolumn{6}{|l|}{ Colon } \\
\hline C16-GluCer & nd & nd & nd & nd & - \\
\hline C24-GluCer & $0.151 \pm 0.028^{a}$ & $0.081 \pm 0.044^{\mathrm{a}}$ & $0.125 \pm 0.036^{\mathrm{a}}$ & $0.118 \pm 0.069^{a}$ & 0.0661 \\
\hline C16-NH ${ }_{2}$ GIPC & nd & nd & nd & $1.901 \pm 0.625$ & $<0.0001$ \\
\hline $\mathrm{C} 24-\mathrm{NH}_{2} \mathrm{GIPC}$ & $0.382 \pm 0.214^{a}$ & nd & $0.279 \pm 0.072^{a}$ & $0.123 \pm 0.056^{b}$ & $<0.0001$ \\
\hline
\end{tabular}

763

764 Values are means \pm standard deviations for 6 and 9 mice in the NC and the three HC-groups,

765 respectively. Mean values within a row, not sharing a same superscript letter, were

766 significantly different at $P<0.05 ;$ nd, not dectected.

767 NC, normo-caloric; HC, hyper-caloric; Con, control; CamC24, camelina meal C24 (from the 768 commercial Céline cultivar rich in C24 fatty acids); CamC16, camelina meal C16 (from the 769 experimental LOH2 cultivar rich in C16 fatty acids). 
772 Figure 1. Body weight curve and body weight gain upon 5 week feeding with the

773 experimental diets.

\begin{tabular}{|cccccc|}
\hline & NC & HC-Con & HC-CamC24 & HC-CamC16 & $P$ value \\
Weight gain (g) $3.47 \pm 1.06^{\mathrm{b}}$ & $8^{2.78} \pm 2.98^{\mathrm{a}}$ & $5.21 \pm 1.24^{\mathrm{b}}$ & $5.08 \pm 1.07^{\mathrm{b}}$ & $<0.0001$ \\
\hline
\end{tabular}

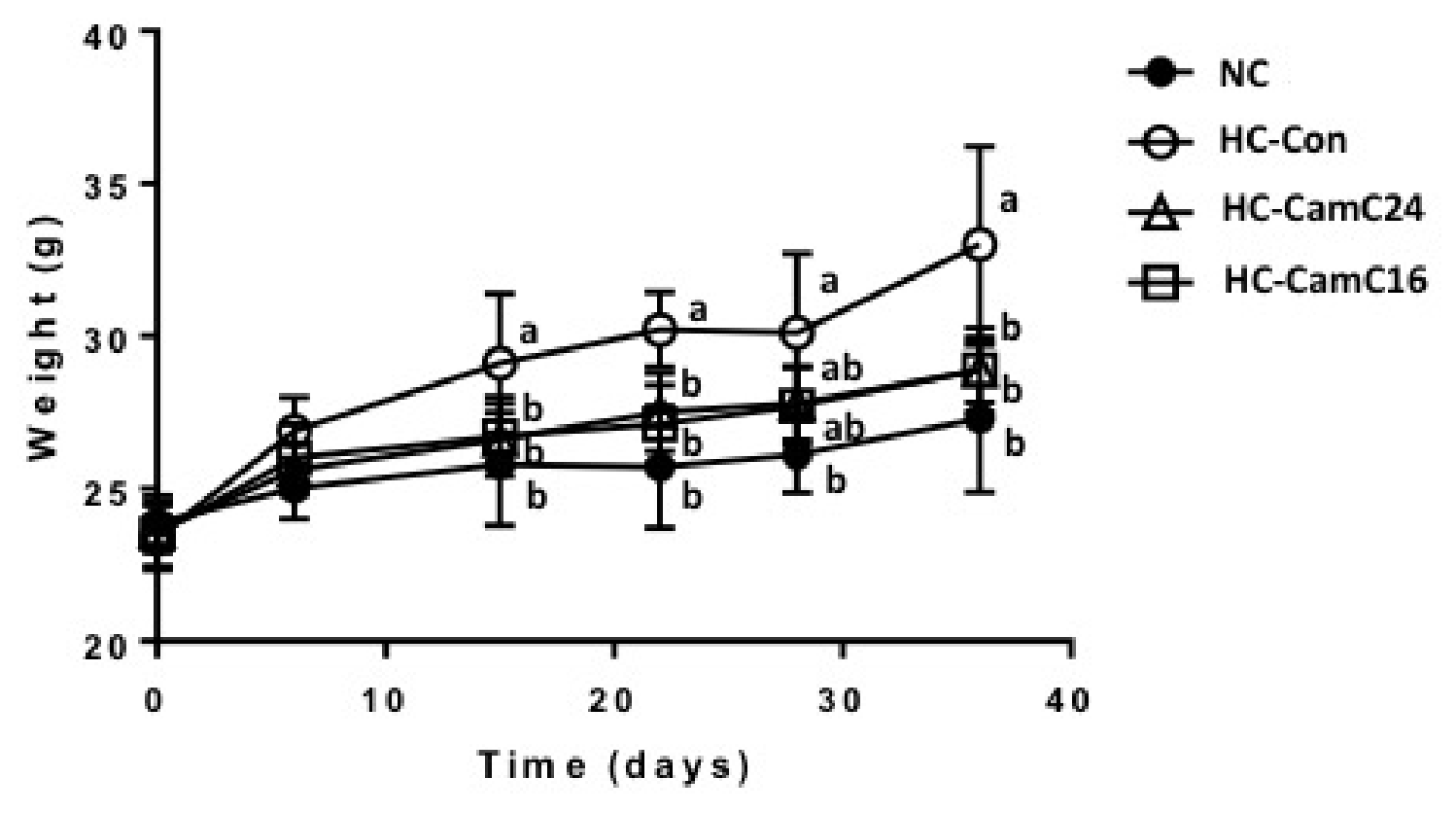

774

775 
776 Figure 2. Plasma kinetics of glucose and insulin during an OGTT after 3 weeks on the

777 experimental diets.

778
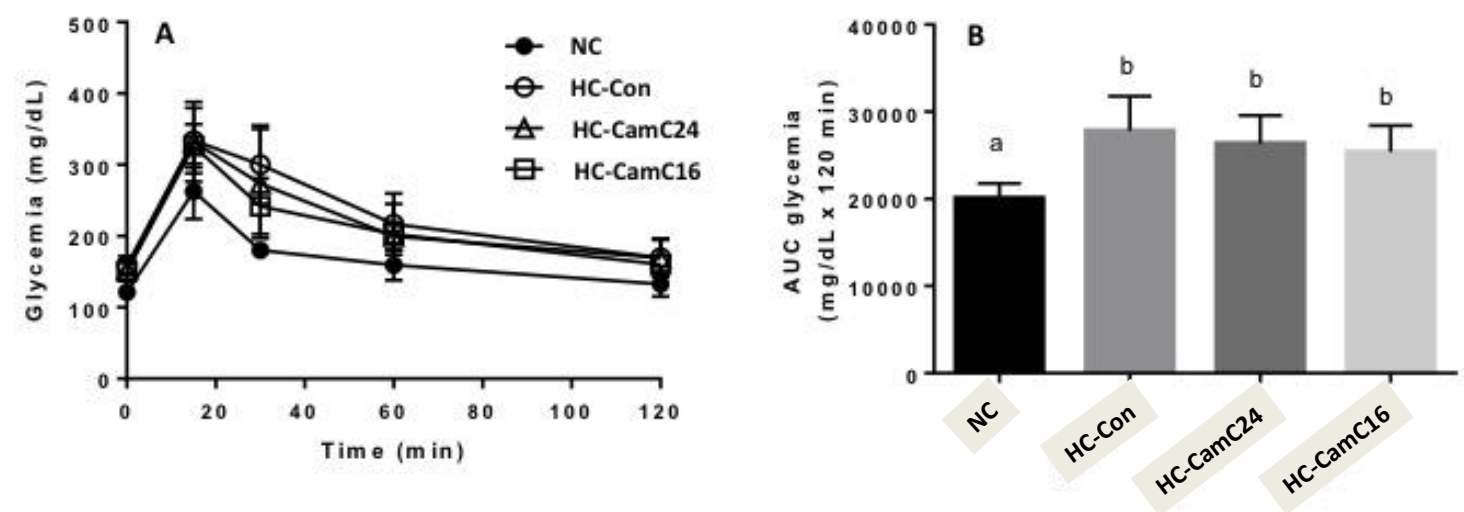

779
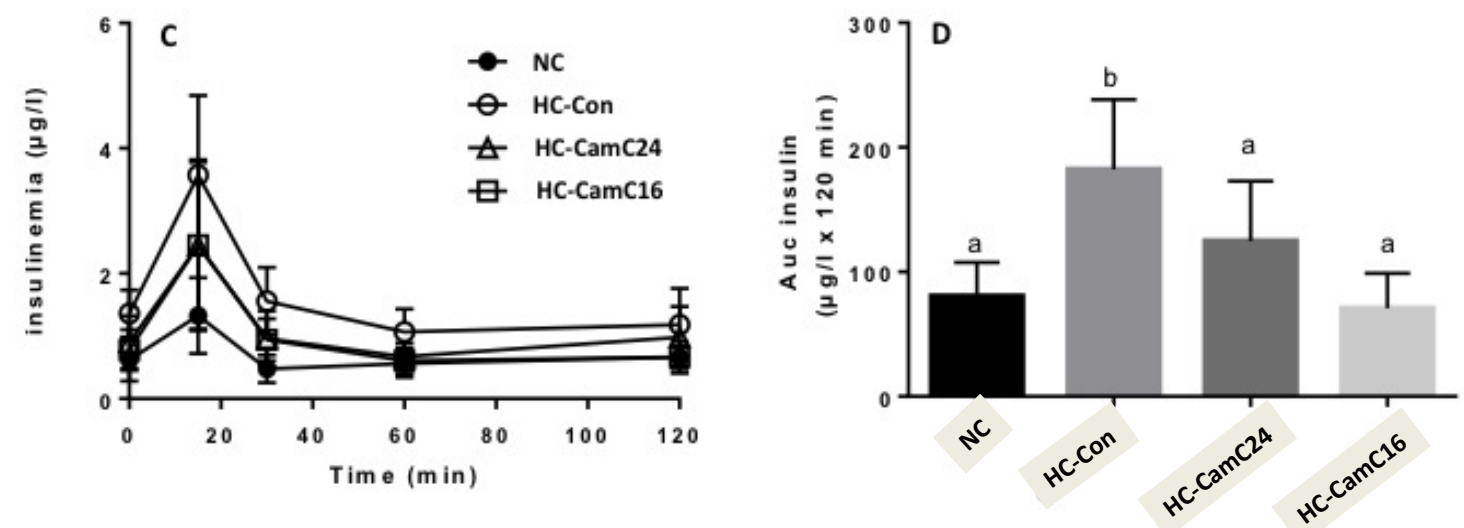

780 


\section{Legend to Figures.}

\section{Figure 1. Body weight curve.}

Body weight (g) was measured longitudinally in the fed state for $37 \mathrm{~d}$. At d0, after they were acclimated to local conditions for 1 week, mice that have been given progressively the HCCon diet during this $1^{\text {st }}$ week, were switched to the HC-Con, HC-CamC24 and HC-CamC16 according to their experimental group.

Values are means \pm standard deviations for 6 and 9 mice in the NC and the three HC-groups, respectively.

NC, normo-caloric; HC, hyper-caloric; Con, control; CamC24, camelina meal C24 (from the commercial Céline cultivar rich in C24 fatty acids); CamC16, camelina meal C16 (from the experimental $\mathrm{LOH} 2$ cultivar rich in $\mathrm{C} 16$ fatty acids).

Figure 2. Plasma kinetics of glucose and insulin during an OGTT after 3 weeks on the experimental diets.

Glycemia (Panel A) and insulinemia (Panel B) have been measured for $120 \mathrm{~min}$ and their respective area under the curve (AUC) were calculated over the same period of time (Panels B and D). Values are means \pm standard deviations for 6 and 9 mice in the NC and the three HC- groups, respectively. Mean AUC values not sharing a same superscript letter, were significantly different at $P<0.05$. 

commercial Céline cultivar rich in C24 fatty acids); CamC16, camelina meal C16 (from the

806 experimental LOH2 cultivar rich in C16 fatty acids).

807

808

809

810

811

812 